DOI 10.37882/2223-2982.2020.12.17

\title{
«ЭТНОГРАФИЧЕСКОЕ ПИСЬМО» АННИ ЭРНО И ЖАНА РУО
}

\section{ETHNOGRAPHIC WRITING \\ OF ANNIE ERNAUX AND JEAN ROUAUD \\ Yu. Kosova}

Summary: This article examines the main features of autobiographical narrative in A. Ernaux and J. Rouaud's works, particularly in La Place and Les Hommes illustres. It highlights the hybridity of their works, which neither quite corresponds to the standards of traditional autobiography, nor to those of autofiction in vogue in French literature at the turn of the centuries. ' «L'écriture plate» (flat writing) by Annie Ernaux is at the crossroads of literature, history and sociology. Without giving up the genre of the novel, J. Rouaud uses fiction as a tool for seeking his own and other people's truth. A. Ernaux and J. Rouaud are considered to be ethnographic writers. Subjectivity is linked to an awareness of the family and collective past. Both authors collect objective traces of the passing era, seeking to grasp the meaning of the social, cultural and economic transformations which affected the French province in the first half of the 20th century. In their indirect autobiographies, returning to oneself involves the reappropriation of the father's life, which is sociologically, geographically and historically determined. We analyze the stylistic characteristics shared by those writers and likely to allow us to label their works as ethnographic writing: the concept of «place» in the titles of the two books, the prevalence of the personal pronoun «we», the depersonalisation of toponyms, various means of creating the polyphonic narrative.

Keywords: autobiographical writing, memory, autofiction, history, subjectivity, ethnographic writing, French province.

\author{
Косова Юлия Анатольевна \\ К.рилол.н., дочент, Российский университет \\ дружбы народов, г. Москва \\ uakossova@mail.ru
}

Аннотация: В статье рассматриваются особенности памятного дискурса в произведениях «Место в жизни» А. Эрно и «Знаменитые люди» Ж. Руо. В ней раскрывается гибридный характер автобиографизма писателей. Их форма «письма о себе» не вписывается ни в рамки традиционной автобиографии, ни «автовымысла» (autofiction), который получил особое распространение во французской литературе рубежа XX-XXI веков. «Плоское письмо» А. Эрно лежит на перекрестке литературы, истории и социологии. Ж. Руо не отказывается от жанра романа, но использует вымысел лишь как инструмент поиска правды о себе и других. А. Эрно и Ж. Руо называют писателями-этнографами. Поиск самоидентичности неразрывно связан с необходимостью осознания семейного и коллективного прошлого. Они фиксирую материальные следы уходящей эпохи, пытаются постигнуть смысл социальных, культурных, экономических преобразований, затронувшие французскую провинцию первой половины XX века. В их «окольных» автобиографиях «возвращение к себе» происходит через воссоздание портрета отца, который оказывается географически, социально и исторически детерминированным. В работе анализируются общие для обоих произведений характеристики, позволяющие отнести их к «этнографическому письму»: идея «места» в заглавии произведений, преобладание местоимения «мы», деперсонализация топонимических обозначений, способы создания полифонического дискурса.

Ключевые слова: автобиографическое письмо, память, автовымысел, история, субъективность, этнографическое письмо, французская провинция.

\section{Введение}

2 начительное место в литературном пейзаже современной французской литературы занимают произведения с очевидной автобиографической доминантой. Возвращение к «рассказыванию историй», которым отмечен рубеж XX-XXI Вв., происходит через вопрошание прошлого в четырех его ипостасях - личное, семейное, коллективное и литературное, - которые оказываются тесно связанными в поиске собственной идентичности и своего места в современной действительности. Потеря интереса к неправдоподобному вымыслу вызывает к жизни разнообразные формы «рассказа о себе» (récit de soi), которые не могут быть отнесены ни к традиционной автобиографии, ни к автобиографическому роману. От традиционной автобиографии их отличает нарушение пакта правдоподобия, ретроспективности и хронологической последовательности в изложении биографических фактов, смысловой завершенности. Соблюдение ономастического пакта совпадения имени автора, рассказчика и главного героя, противоречащее сосуществованию в одном текстовом пространстве реальных и вымышленных историй, отдаляет новые автобиографии от автобиографического романа, в котором события жизни писателя являются всего лишь материалом для вымысла.

«Автовымысел» (autofiction) представляет собой референтное жанровое обозначение, без которого не обходится ни один современный французский литературовед, изучающий произведения о личном и семейном прошлом. Впервые получив теоретическое обоснование в предисловии к роману «Сын/Нити» Сержа Дубровски в 1977 г., эта новая гибридная форма письма о себе, обозначенная как «вымысел об абсолютно реальных событиях и фактах» [4], оказалась в центре литературной жизни Франции. Об этом свидетельствует интерес к исследованию параметров автофикциональности таких ученых, как В. Колонна, Ж. Женетт, Ж. Лекарм, Ф. Гаспарини, В. Грель, М. Дарьесек, А. Генон и др. «Автовымысел» 
позволил, с одной стороны, по-новому взглянуть на произведения М. Пруста, С.-Г. Колетт, М. Лейриса, М. Дюрас и др., с другой стороны, открыл для современных авторов неограниченные строгими жанровыми канонами возможности самопознания. Его называют «биографией неизвестных» [3. Р. 25]. В отличие от традиционной автобиографии, автофикциональные произведения не создаются на завершающем этапе творчества и не являются синтезом жизненного опыта увенчанных славой личностей, как, например, у Ж.-Ж. Руссо. Они пишутся в течение всей жизни. В них писатель рассматривает каждый раз с нового ракурса свое прошлое и настоящее в попытке приблизиться к пониманию самого себя, к разрешению внутренних конфликтов. В «автовымысле» акцент делается на поиск скрытой, недоступной правды о себе через письмо, близкое к психоаналитическому дискурсу. По словам В.Д. Алташиной, вымысел является здесь не самоцелью, а «используется в качестве инструмента для поиска самоидентичности» [1. С.16].

В произведениях некоторых писателей возвращение к себе происходит окольным путем, через повествование о «другом», чаще всего о своих родителях. Эготическая интроспекция «автовымысла» уступает место желанию запечатлеть объективные следы уходящей эпохи: особенности быта и труда, языка, манеру общения со «своими» и «чужими», классовое членение городского пространства и т.д. В центре повествования оказывается изменение провинциальной действительности на протяжении XX в., а также жизнь социальных групп населения, которые редко становились предметом критического осмысления в послевоенной французской литературе - крестьян, рабочих, мелких коммерсантов.

Известный французский критик Д. Виар называет «этнографическим письмом» автобиографические произведения, в которых личное и семейное прошлое социально и географически детерминированы и могут быть раскрыты и осознаны только через связь с жизнью сообщества, коллектива, к которому принадлежал автор-рассказчик и его предки. Эта форма «письма о себе» развивается, прежде всего, в творчестве А. Эрно и Ж. Руо - двух ярких представителей французской литературы конца XX - начала XXI вв., лауреатов престижных французских литературных премий.

А. Эрно и Ж. Руо сближает общность провинциального происхождения. Они вышли из среды мелких коммерсантов, предками которых были крестьяне и ремесленники. Ж. Руо родился в небольшом городке Камбон, недалеко от Нанта. Его родители занимали некоторое «привилегированное» положение среди своего окружения, так как отцу принадлежал редко встречающийся во французской глубинке середины XX в. специализированный магазин посуды, а дедушка по материнской линии был известным в своем регионе мастером по по- шиву мужских костюмов, был принят в замке и собирал в своем доме местную интеллигенцию. А. Эрно провела детство в рабочих кварталах Лилльбонна и Ивето, недалеко от Руана. Родителям писательницы, родившимся в бедных крестьянских семьях, пришлось пройти сложный и долгий путь, чтобы стать владельцами небольшого бакалейного магазина-кафе и позволить дочери получить хорошее среднее образование в частой школе, открыв для нее двери в университетский и буржуазный мир. Раскрытие и преодоление конфликта, вызванного переходом из экономически и культурно подчиненной среды в доминирующий общественный класс, лежит в основе ее произведений.

Имена А. Эрно и Ж. Руо встречаются во всех крупных монографиях рубежа веков, в которых анализируются основные тенденции развития современной французской литературы [8], [11], [12]. Кроме того, Ж. Руо известен еще и тем, что является одним из немногих французских писателей, удостоенных престижной Гонкуровской премии за первый роман («Поля чести» 1990 г.). Однако их творчество мало знакомо российскому читателю и недостаточно изучено в отечественном литературоведении. «Место в жизни» А. Эрно в первый раз было опубликовано в 1986 г. в журнале «Иностранная литература» в переводе Г.Н. Ерофеевой. Роман «Знаменитые люди» Ж. Руо еще не был переведен на русский язык.

В центре настоящего исследования находятся два автобиографических произведения: «Место в жизни» (La Place, 1983 г.) А. Эрно и «Знаменитые люди» (Les Hommes Illustres, 1993 г.) Ж. Руо. Автор-рассказчик занимает в них позицию свидетеля, а поиск себя определяется необходимостью осознать, чем была жизнь отца, с которым по разным причинам нарушилась связь. Отец Ж. Руо умирает, когда будущему писателю было всего двенадцать лет. Молчание отца А. Эрно связано, как пишет сама писательница в «Место в жизни», с «классовой дистанцией», возникшей между ними в ее школьные годы. Оба писателя возражают против отнесения их произведений к «автовымыслу». Для них автобиографизм лежит в другой плоскости $\neg-$ плоскости этнографического письма. Необходимо определить, что сближает их подходы в обретении прошлого, какие нарративные стратегии они используют для превращения субъективного опыта в демонстрацию общих явлений.

Осуждение. Смерть отца является для обоих писателей определяющим моментом в их творчестве. Начиная с «Места в жизни», А. Эрно решительно заявляет об отходе от романного жанра, создавая свою неповторимую манеру повествования о прошлом $\neg-$ «плоское письмо» (écriture plate). Писательница воссоздает в этом произведении, художественное новаторство которого было отмечено литературной премией Ренодо в 1984 г., не столько субъективный, сколько социологический пор- 
трет отца. Ж. Руо дебютирует в литературе уже в зрелом возрасте с романами «Поля чести» (1990 г.) и «Знаменитые люди» (1993), за которыми последуют еще три произведения на стыке правды и вымысла, посвященные поиску себя через воспоминание о родных людях. Движущей силой этой необычной автобиографической пенталогии является попытка разобраться в причинах рано оборвавшейся жизни отца и критическое осмысление разрушительных последствий этого события для формирования собственной идентичности.

Ключевой характер смерти отца для самоидентификации отражается в сходной композиции двух произведений. У А. Эрно рассказ о кончине отца образует рамочную конструкцию, обрамляющую фрагментарную хронику его жизни. Первая глава романа «Знаменитые люди» Ж. Руо построена по тому же принципу. Вся послевоенная жизнь отца рассказчика как бы втянута в события трагического дня его смерти: сильное недомогание, которое он почувствовал днем, пытаясь обрубить ветки дерева, в которые запутались во время бури электрические провода, заканчивается его трагическим падением посреди ванной комнаты на фоне вновь разбушевавшейся стихии. Между двумя этими моментами умещается на ста страницах целая созидательная жизнь простого провинциала, стремящегося превратить свой дом в «виллу императора Адриана» и построить в бретонской провинции «вавилонскую башню», объединяя вокруг себя и своих идей (театр, литература, футбол, бесконечные беседы, строительство, городские праздники и т.д.) соседей и друзей.

Для Ж. Руо смерть отца - это далекое детское воспоминание, лакуна памяти, изначальная травма, которая мешает ему найти свое место в жизни. Для того чтобы, по выражению Ж. Гусдорфа, «вернуться к себе», стать наконец-то самим собой, а не просто сыном «великого Жо», выросшим «в его тени», он должен восстановить то, чем была жизнь отца, вообразить его мысли, радости, сомнения и страхи, определить не только его силу, но и его слабость. Приблизив отца к себе, Ж. Руо преодолевает в процессе письма Эдипов комплекс, и плаксивый сирота превращается в признанного и уверенного в себе писателя.

Писать об отце А. Эрно побуждает ощущение вины перед ним и чувство стыда, она хочет восстановить разорванную классовой неприязнью связь. Она ощущает себя «классовой перебежчицей» («transfuge de classe»), которая отдалилась от родителей и предала свою среду происхождения для того, чтобы узаконить вхождение в буржуазный мир в результате учебы в университете и удачного замужества. Слово «предательство» появляется в эпиграфе, взятом из Ж. Жене: «Я осмеливаюсь дать объяснение: писать - это последнее прибежище для того, кто предал» (здесь и далее перевод мой - Ю.К.).
Писательница возвращает к жизни образы родителей во всей «славе» их прозаического, скудного, постыдного в глазах элиты существования с его постоянной нуждой, теснотой жилья, в котором нельзя скрыть от другого даже проявления физиологической жизни собственного тела. Она показывает родителей такими, какими они были, не скрывая отсутствие хороших манер и культурных интересов, их грязный французский язык, смешанный с патуа, разговоры на повышенных тонах, приниженность перед теми, кто находится выше по социальной лестнице. Однако неприглядность такого существования, которая в подростковом возрасте порождала стыд, снимается в настоящем письма с помощью библейской метафоры «славные тела» («les corps gloriaux»), отсылающей к событию Воскресения Христа во всей славе и силе после позорной и мучительной смерти на Кресте. Это образ служит не для создания иронии, а, наоборот, для утверждения образа жизни родителей и их жизненного пути как реальности, которая, как и любая другая реальность, например, правящего образованного класса, достойна уважения, признания и своего места в литературе.

Для этого А. Эрно вскрывает противоречивый характер буржуазных концептов «достоинство» («dignité») и «отличие, изысканность» («distinction»), которые связаны в первую очередь с происхождением, культурой поведения и образованностью, но в то же время являются источником отчуждения. Им противопоставляется народный концепт «гордость» («fierté»). Однако в «Место в жизни» его смысловое содержание не совпадает со словарным значением. Для отца автора-рассказчицы «гордость» - это, прежде всего, возможность работать своими руками, т. е. «гордость труда» («fierté de travail»). Пьяницы и гуляки осуждаются им как «негордые люди» («des gens pas fiers donc»). А. Эрно разоблачает социальную дискриминацию, доказывая, что достоинство человека определяется его силой противостоять житейским невзгодам и способностью не опускаться, «держать свое место» («tenir sa place»), в каком бы ряду социальной иерархии оно не находилось. В произведении встречаются слова «реабилитация» и «искупление». Как и Ж. Руо, автору «Место в жизни» нужно «вернуться к себе», восстановив в процессе письма разорванную с родителями связь. Местоимение «я» появляется в тексте произведения при упоминании о школьных годах рассказчицы и знаменует разрыв, триумф индивидуальности дочери, осознавшей свое превосходство над простоватым и малообразованным отцом. Напротив, обретение и «реабилитация» забытого языка и видения мира детства, потерянной общности с родителями сопровождается возвращением в речь автора местоимения «мы»: «Я теперь часто говорю «мы»» [7 Р. 61].

Выделим общие черты, которые позволяют охарактеризовать произведения А. Эрно и Ж. Руо как «этнографи- 
ческое письмо».

Прежде всего, нужно подчеркнуть общность между заглавиями двух произведений. В них заложена идея «места», «ранга», которое занимает человек в жизни. Ни А. Эрно, ни Ж. Руо не ставят перед собой цель представить хронологически последовательную историю своей жизни и жизни отца, в которой отразились бы ключевые этапы становления личности, что характерно для традиционной автобиографии. Согласно Ф. Лежену, автобиография - это «ретроспективное прозаическое повествование реального человека о себе, первостепенное значение в котором имеют события частной жизни и история становления личности рассказчика» [9 Р. 10].

Выбор заглавия произведения «Место в жизни» объясняется тем, что А. Эрно сосредоточивается главным образом на социально-географической траектории жизни отца (батрак, рабочий, владелец бакалеи-кафе), а не на каких-то единственных в своем роде, особенных событиях. Ее личное становление неразрывно связано с осознанием места отца в социальной структуре общества, существующей дистанции между господствующими и господствуемыми. В произведении актуализируются почти все значения многозначного французского слова «place»: «место в пространстве», «работа, должность», «ранг в социальной иерархии», «место в пространстве дома» и т.д. Страхи отца определяются производным от слова «место» прилагательным «неуместный» (déraciné).

Заглавие романа Ж. Руо «Знаменитые люди» основано на интертекстуальной перекличке с «Жизнью замечательных людей» Плутарха. Употребление грамматической формы «des» многозначно. С одной стороны, отец рассказчика выделяется среди других простых провинциалов и ставится в один ряд со знаменитыми деятелями прошлого. С другой стороны, одним из «знаменитых людей» оказывается не только он, но и все его современники, достойно пережившие Вторую мировую войну, все те неприметные провинциалы, носители раблезианского духа народной французской культуры, которые не утратили жизнелюбие и ироничное отношения к жизни в самых сложных ситуациях. В послевоенные годы отец рассказчика пытается найти свое место в новой реальности. Поиск места в жизни и эволюция жизненных стремлений Жозефа, в молодости мечтавшего о великой судьбе за пределами своего родного города, резюмируется следующим образом: «...Как если бы он решил, что его место было здесь среди этих людей» [10. Р. 72]. Он осознает свою неразрывную связь с землей, на которой родился, и окружающими его людьми. Писатель рисует «легендарную географию» перемещений современного Одиссея по стране, который неизменно возвращается в родной город. Значимость понятия «место» метафорически воплощается в карте Франции, висящей в его кабине- те: цветные гвоздики обозначали не только этапы его будущих рабочих поездок, но важные жизненные ориентиры, связывающие прошлое и настоящее. Это люди, его современники, встреченные повсюду во Франции, и история страны, воплощенная в древних камнях.

У обоих писателей этнографическое бытописание разворачивается на конкретном историческом фоне. Речь идет о послевоенном времени, названном во Франции «славным тридцатилетием», а также о годах войны и немецкой оккупации. Писателям удается в небольших по объему произведениях (чуть больше ста станиц) запечатлеть события почти целого века и изменение образа жизни сквозь призму субъективного восприятия переживших их людей.

А. Эрно воссоздает условия существования непривилегированных слоев населения в исторической французской провинции Нормандия, охватывая период с начала XX века (времени рождения отца) до 80-х гг. (времени его смерти). Она показывает, что спасением от суровой жизни безземельных крестьян, обобщенной с помощью прилагательного «мрачный», является введение обязательной военной службы в начале XX века, что позволило крестьянским детям увидеть наконец-то «мир», и индустриализации страны, когда жизнь рабочего с фиксированной зарплатой, выходными днями, теплыми цехами воспринимается как подарок цивилизации. Не остается без внимания Народный фронт с кратковременной надеждой на изменение положения пролетариата и война с массовым исходом французов с занятых врагом территорий и последующим возвращением домой, воспоминания о голоде и смерти близких. Писатель говорит о процессе послевоенного восстановления страны и улучшения жизни всех слоев населения, о возникновении общества потребления, о появлении социальной защиты населения и т.д. Бытописание в произведении «Место в жизни» дается в форме перечисления и близко к констатации социологических фактов в исследованиях П. Бурдье, его понятию «габитуса». Большие временные интервалы обобщаются в серии номинальных предложений: «Крестное знамение над хлебом, церковные службы, празднования Пасхи» [7. Р. 28]; «Утренняя и вечерняя дойка коров, октябрьская морось, яблоки, закидываемые в давильню, сгребаемый лопатой куриный помет, тепло и жажда. А также пирог с бобом на Крещение, чтение «Альманаха Вермот», жареные каштаны...» [7. Р. 33]; «Всегда теплое кафе, радио в глубине зала, вереница завсегдатаев с семи часов утра до девяти вечера, привычные слова входящих и ответы: «Привет всем - И тебе тоже здравствуй...» [7. Р. 76]. В исторических и литературных аллюзиях раскрываются особенности эпохи: «Когда я читаю Пруста или Мориака, мне не верится, что они рассказывают о времени, когда мой отец был ребенком. Средневековье - вот обстановка его жизни» [7. Р. 29]. 
В романе «Знаменитые люди» Ж. Руо возрождает образ Бретани первой половины XX века с ее пасторальными пейзажами со стадами коров, плохими проселочными дорогами, яблоневыми садами, реликтами языческих святилищ и древними романскими храмами, народнохристианскими легендами, спорами в кафе любителей сидра («самая пьющая провинция Франции»), бесконечными религиозными процессиями и праздниками. Он показывает мир, в котором ключевыми концептами являются «общинный», «религиозность», «связь с природой». В отличие от документальности А. Эрно, писатель запечатлевает следы уходящей эпохи в длинных и витиеватых фразах, включающих в себя целый микрокосм и напоминающих стиль М. Пруста. Такое переплетение впечатлений и образов позволяет ему передать взаимосвязь и преемственность между людьми, природой и социальными явлениями, характерными для традиционного общества.

Основной конфликт произведения, в который включается отец рассказчика, заключается в противопоставлении традиционности и современности. В результате Второй мировой войны, с одной стороны, и послевоенной государственной политики Франции в области сельского хозяйства, направленной на консолидацию земель («le remembrement»), с другой стороны, формируется новый безликий географический и социальный облик региона. Столкновение между старым и новым выражается в серии риторических вопросов: «Как сгруппировать то, что рассеяно: поля, дома, животных? Как рассеять то, что объединено: поколения, память людей?» [10. Р. 43]. Создание прогрессивного землепользования в Бретани иронически представлено как продолжение унифицирующей политики сначала французских королей, а затем и деятелей Великой французской революции. Ж. Руо воспринимает своего отца, крепкими узами привязанного к родной земле («земля-избранница») и противостоящего распаду людских связей («главное для него - не быть одному»), как жертву этой «бескровной войны». Его преждевременная смерть объясняется невозможностью найти компромисс между стремлением к прогрессу и страхом перед потерей привычных ориентиров: «Где найти новые ориентиры в этой грядущей пустыне?» [10. P. 82].

Каждый из двух писателей по-своему переосмысливает место отца в изменяющейся Франции второй половины XX века. В «Знаменитых людях» отец рассказчика представлен, благодаря своим многочисленным талантам, неординарным для своей провинциальной среды человеком и настоящим героем, что передается в серии таких номинаций, как «наш великий человек», «наш Ленотр», «Леонардо да Винчи», «Великий Жо». Образ Жозе$ф а$, коммерческого представителя одного из магазинов Нанта к западу от Луары, неотделим от сменяющихся машин, на которых он бороздил лабиринты проселочных дорог. Машина является метафорой выхода за отведенные ему временем и средой границы провинциального существования, средством приобщения к культуре и истории всей страны, инструментом самореализации.

Нужно отметить, что такие артефакты, как велосипед и машины, играют важную символическую роль в произведениях обоих писателей. Они выступают не только материальными следами рождающегося общества потребления и знаком улучшения жизненных условий в послевоенные годы, но и метафорой поступательного движения вперед, которое характеризовало обоих мужчин, символом перехода между прошлым и настоящим.

Отец А. Эрно, малообразованный крестьянин, ставший сначала рабочим, а затем мелким коммерсантом, на первый взгляд, не может получить статус литературного героя. Незаметность его судьбы подчеркивается с помощью антитезы: в отличие от тысяч его соотечественников, ему даже не довелось воевать на фронтах двух мировых войн, так как он был «слишком молодым» для первой и «слишком старым» для второй. Комментарии рассказчицы, построенные на отрицании, подчеркивают его ординарность, лишают его образ заметных характеристик: «Он не входил в состав никакого сообщества, только платил взносы в торговом союзе, не участвуя в чем-либо» [7. Р. 20], «ни бездельник, ни выпивоха, ни гуляка», он не интересовался «ни профсоюзами, ни политикой» [7. Р. 35].

Однако в редких метафорах раскрывается внутренняя сущность отца. Он предстает молчаливым борцом и созидателем, стремящимся до конца своей жизни выйти за предназначенные ему местом и средой рождения «унизительные барьеры» существования бедняков. Он называется «перевозчиком между двумя берегами», когда на своем велосипеде отвозил дочь в школу, и уподобляется «лежащей птице» после своей смерти. Желание доказать, что простые люди достойны называться героями в жизни и в литературе, подчеркивается также через единичное употребление книжного грамматического времени passé simple, которое вводит слово «герой». Во время войны отец рассказчицы помогал снабжать семьи своих соседей продуктами питания, доставляя их издалека на прицепленной к велосипеду тележке. Этой постоянный подвиг возвел его в ранг героя в своих собственных глазах, и в глазах окружения: «Он считали в долине Больбека героем снабжения. Не по собственному выбору, но по необходимости. Впоследствии уверенность в том, что он сыграл какую-то роль, что он по-настоящему жил в те годы» [7. Р. 49]. А. Эрно пишет как раз для того, чтобы опровергнуть обесценивающий взгляд на отца, определить значащую линию его жизни, которую можно резюмировать словами «жить по-настоящему», быть «человеком», то есть тем, кто сам выбирает свое место в жизни. Дед рассказчицы, безземельный батрак, бил 
жену и детей, так как для него «злость была жизненно необходимой пружиной, силой, чтобы сопротивляться нищете и думать, что он человек» [7. Р. 25]. Эволюция отца рассказчицы подчеркивается пропастью в понимании значения слова «человек» у двух мужчин. Собирая объективные следы существования отца, она пытается уловить некую коллективную правду, которая определяла видение мира, стремления, силу и достоинство отца как представителя определенной социальной группы.

Для того чтобы «вырваться из ловушек индивидуального» [7. Р. 45], А. Эрно и Ж. Руо изменяют названия городов, в которых прошло их детство. В «Место в жизни» топонимы обезличиваются, так как писательница сводит названия Лилльбонна и Ивето к первым заглавным буквам L.и Y. B «Знаменитых людях» название родного города писателя Камбон преобразуется в топоним Рандом, сходный по звучанию. Этот словесный ребус расшифровывается как «ранг (место) человека» («rang d'hommes») и перекликается с названием романа.

«Этнографическое письмо» А. Эрно и Ж. Руо отличается как от традиционной автобиографии, так и от «автовымысла» употреблением личных местоимений. Отказ от местоимения «я» является попыткой растворить субъективный опыт в более широкой реальности, превратить его в историческое свидетельство коллективного характера, в котором читатели могут обрести частичку своего прошлого. В памятном дискурсе обоих писателей преобладает местоимение «мы» в двух грамматических формах «on» и «nous». Голос автора-рассказчика сливается с голосами как членов семьи, так ее окружения, объединенных общим взглядом на жизнь, схожими радостями и горестями.

Субъективность и индивидуальность, присущая автобиографии и «автовымыслу», нарушается в «этнографическом письме» А. Эрно и Ж. Руо созданием полифонического дискурса. Для того чтобы описать действительность своего детства, недостаточно зафиксировать в тексте материальные следы существования простых людей: предметы быта, места, привычки, поведение. Для писателей важно дать читателю возможность услышать голоса забытого мира. А. Эрно объясняет языковые особенности своего произведения следующим образом: «В этом проекте я держусь как можно ближе к услышанным когда-то словам и фразам, выделяю их иногда с помощью курсива. Так как эти слова рассказывают о границах и цвете мира, в котором жил мой отец, в котором я тоже жила...» [7. Р. 46].

Полифония у обоих писателей опирается на различные способы введения в текст чужой речи. Помимо прямой речи и несвободной прямой речи, в «Знаменитых людях» Ж. Руо реплики героев возникают неожиданно внутри повествовательных или описательных отрывков без всякого графического или синтаксического выделения, оживляя повествование и делая читателя участником происходящего: «Тот, кто нас привез сюда, просит нас раздвинуть заросли больших голубых цветов. Мама предостерегает, вы испачкаетесь, и, видя нашу нерешительность, Жозеф, ты намочишься, решается нырнуть в покрытые капельками дождя цветы, цепляется за что-то тяжелое, прогибается всем телом назад, ногами ищет опоры на скользкой траве и затем, Жозеф, ты с ума сошел, выкатывает из кустов внушительных размеров камень ...» [10. Р. 74].

У.А. Эрно почти нет прямой речи, а диалогическое пространство текста создается при помощи фраз и отдельных слов, заключенных в кавычки. Чаще всего так передаются разговоры между родственниками, родителями и детьми, посетителями кафе, их размышления об условиях своего существования: «осознание, что «у нас не очень хорошо», «чувство, что «это судьба». Самым распространенным способом включения чужих голосов является использование курсива. Выделенные курсивом слова и выражения имеют просторечный характер, в них отражается видение мира той социальной группы, к которой принадлежал отец и сама рассказчица в детстве. Вот некоторые из них: ne pas prendre ouvrier («не выйти замуж за рабочего»), retomber ouvrier («вернуться в рабочие»), taper sur le système («бить по мозгам»), ne pas savoir faire son lit («гулять»), porter une odeur sur soi («провонять») и т.д. В маркированных курсивом выражениях, относящихся к литературному языку, автор указывает на грамматические ошибки, сделанные родителями. Например, вместо «vivre en plein air», они говорили «vivre au plein air». Границы между двумя мирами французского общества, очерчиваются также различным пониманием значения одних и тех же слов, что обусловлено условиями жизни и уровнем образования. Отец и дочь вкладывают разный смысл в такие слова, как «культура», «земля», «работать», «учиться», «жить». Так, например, слово «культура» было лишено для отца рассказчицы духовного содержания, сохраняя только один экономический смысл - «возделывание сельскохозяйственный культур»: «После возвращения из армии он не захотел вернуться к культивированию земли (здесь - culture). Он всегда так называл работу на земле, культура в другом смысле, духовном, ему была бесполезна» [7. Р. 34].

Важное отличие между памятным дискурсом А. Эрно и Ж.Руо заключается в их отношении к жанру романа. Начиная с «Места в жизни», А. Эрно решительно отказывается от вымысла и разрабатывает новую форму письма о себе, которую назовет позже «авто-социо-биографией». Она считает, что вымысел невозможен в повествовании о полной лишений жизни ее предков, так как он исказил бы под маской популизма, иронии или сострадания облик родителей, борющихся за выживание, скрыл бы существование во французском обществе двух реаль- 
ностей - «высших» и «низших» людей: «С недавнего времени я знаю, что роман невозможен. Для того чтобы рассказать о жизни, подчиненной требованиям житейской нужды, я не имею права ни вставать на сторону искусства, ни пытаться сделать что-то «увлекательное» или «волнующее» [7. Р. 24]. В подходе А. Эрно ощущается перекличка с идеями Р. Барта, для которого язык традиционного романа является носителем доминирующей в обществе буржуазной идеологии. Ф. Дюга-Порт полагает, писательница хотела рассказать о переходе из одного общественного класса в другой, «о вызванном им бунте и чувстве вины на языке доминируемых» [5. Р. 120]. В основе «плоского письма» лежит простая констатация фактов, ограниченность стилистических приемов художественного изображения действительности, использование народных выражений и оборотов, что позволяет очертить словами границы мира родителей, далеких от буржуазной литературы и культуры, воссоздать непоэтическую реальность их жизни.

Ж. Руо, напротив, на обложке своих книг указывает на их отнесенность к жанру романа. Недостоверность памяти заставляет его обращаться к вымыслу для того, чтобы вообразить недостающие факты и связать разрозненные воспоминания. Вымысел дает Ж. Руо свободу для критического осмысления и вопрошания прошлого, является инструментом постижения ускользающей правды, того, как «человеческая судьба меняется под влиянием событий», как время и место отражаются на судьбах и характерах людей [2. Р. 227]. Его манеру письма называют «воображаемым воспоминанием» (Х. О. Мюллер) или «воображаемым реальным» (Ж. Сальван).

В имплицитной перекличке с М. Прустом раскрывается невозможность вернуть прошлое с помощью произвольного воспоминания. Различные нарративные стратегии раскрывают трудности припоминания. Для памятного дискурса Ж. Руо характерны серии риторических вопросов, употребление условного наклонения и модального выражения «может быть», дискретность и фрагментарность воспоминаний. У А. Эрно изложение автобиографических фактов чередуется с металитературными размышлениями о трудности создания объективного портрета отца, повторением глаголов «знать» и «помнить» в отрицательной форме: «је ne sais plus», «je ne me souviens pas». Основные этапы работы над книгой точно датируются. Оба писателя сосредоточены, скорее, на процессе воспоминания, чем на его результате.

\section{Зак^ючение}

Социальная действительность и история неизменно присутствуют в произведениях А. Эрно и Ж. Руо. Их автобиографизм отличается необычным сочетанием субъективного письма, связанного с поиском самоидентичности, с необходимостью вернуться к своим истокам, запечатлеть следы уходящей эпохи, обнаружить скрытые конфликты в существовании простых людей во второй половине XX века, т.е. через индивидуальное воспоминание заставить заговорить молчащую коллективную память.

Похожие нарративные стратегии служат у обоих писателей для создания полифонического дискурса, в котором «я» рассказчика растворяется в коллективном «мы». В отличие от автофикциональной литературы, самоанализ интересует их только как способ обнаружения в индивидуальной судьбе некой коллективной правды, и, наоборот, понимание себя невозможно без «другого». Именно поэтому в центре повествования в «Место в жизни» А. Эрно и «Знаменитые люди» Ж. Руо находится фигура отца. Только приблизившись к пониманию реальности его жизни, рассказчик может понять самого себя. Постижение ускользающего прошлого возможно только путем создания особого языка, который очертил бы более точно, чем любые объективные следы, границы мира родителей. По словам А. Эрно, правда может быть «достигнута только словами (то есть ни фотографии, ни воспоминания, ни свидетельства членов семьи не могут дать эту правду)» [6. Р. 25].

Для того чтобы раскрыть суровые условия существования родителей А. Эрно отрекается от романного жанра и создает новую форму письма о себе - «плоское письмо» (écriture plate) - на стыке литературы, социологии и истории. Вымысел позволяет Ж. Руо вписать с помощью исторических и литературных аллюзий жизнь отца в широкую историческую перспективу и, показав разрушительный характер истории, примириться с его потерей.

В обоих произведениях рассказчик выступает в роли свидетеля, повествуя об увиденном и пережитом. Успех А. Эрно и Ж. Руо объясняется тем, что многие читатели узнали в созданных ими этнографических фресках знакомую им провинциальную жизнь послевоенной Франции, а также обнаружили собственные сомнения, страхи, которые были связаны с осознанием существующих во французском обществе того времени социальных и географических барьеров.

ЛИТЕРАТУРА

1. Алташина В.Д. Autofiction в современной французской литературе: лего из эго // Известия Южного федерального университета. Филологические науки. 
2014. № 3. C. 12-22.

2. Baty-Delalande H. L'homme nouveau». Entretien avec Jean Rouaud // Lire Rouaud. Lyon: Presses universitaires de Lyon, 2010. P. 227.

3. Carrier-Lafleur T. Proust et l'autofiction: vers un montage des identités // www. revue-analyses. org. 2010. Vol. 5. No. 2. Pp. 1-25.

4. Doubrovsky S. Fils. Paris: Galilée, 1977.

5. Dugast-Portes F. Annie Ernaux: étude de l'œuvre. Paris: Bordas, 2008. 191 p.

6. Ernaux A. La place. Paris: Gallimard, 1988. 128 p.

7. Ernaux A. La place. Paris: Gallimard, 1983. $128 \mathrm{p}$.

8. Le roman français au tournant du XXlème siècle / Sous la direction de Bruno Blanckeman, Aline Mura-Brunel et Marc Dambre. Paris: Presses Sorbonne Nouvelle, $2005.589 \mathrm{p}$.

9. Lejeune Ph. L'autobiographie en France. 2 éd. Paris, 1998. 192 p.

10. Rouaud J. Des hommes illustres. Paris: Les Éditions de Minuit, 1999. 173 p.

11. Viart D. Le roman français au XX siècle. Paris: Armand Colin, 2011. $224 \mathrm{p}$.

12. Viart D. La littérature française au présent - Héritage, modernité, mutations. Paris: Editions Bordas, 2005. 512 p.

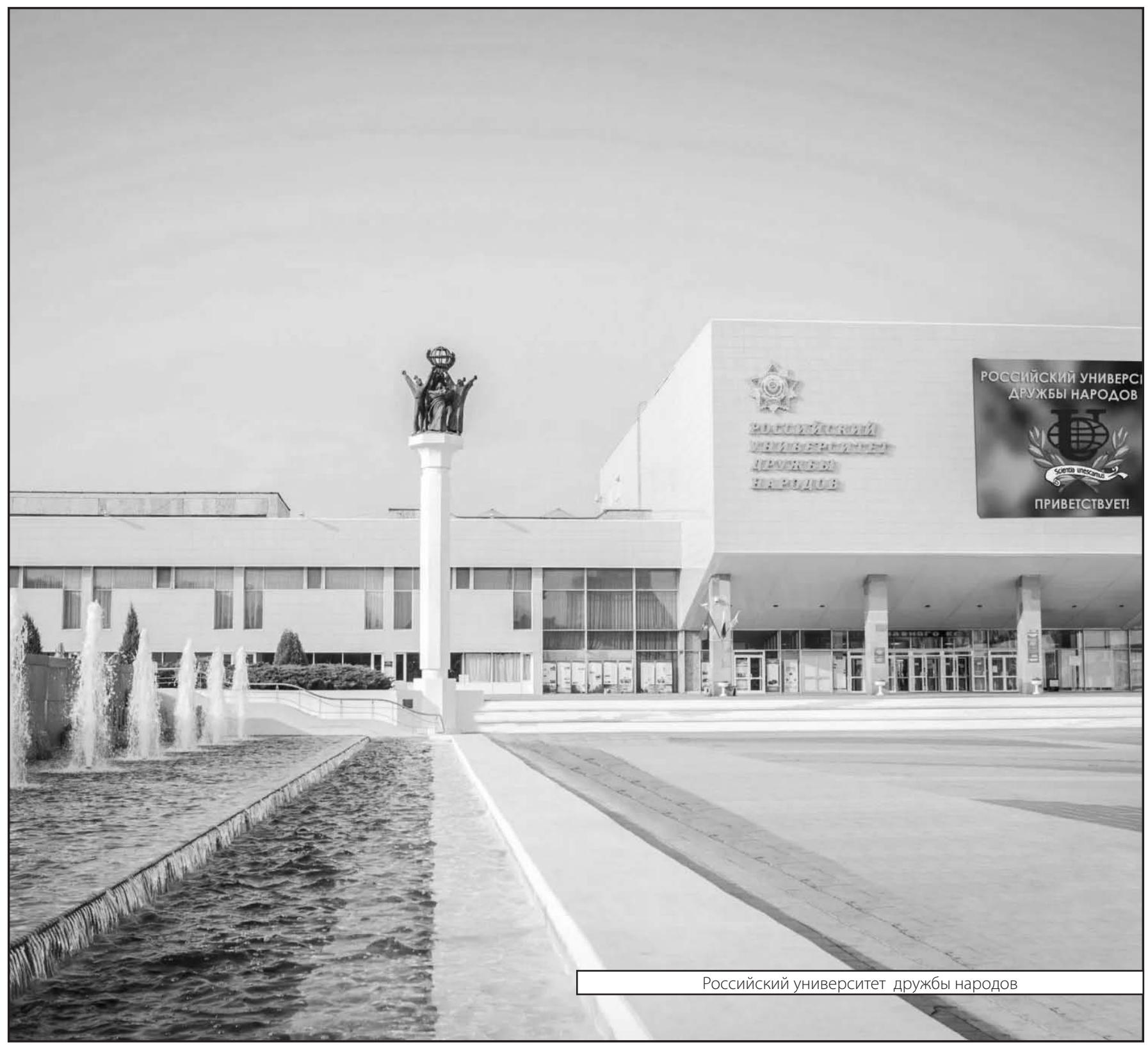

